\title{
Physico-Chemical Characterization of Dentinal Surface Treated with Atmospheric- Pressure Plasma
}

\author{
E. Alfaro-Mayorga,,${ }^{a}{ }^{,}$J. Rodríguez-Rojas, ${ }^{b}$ M. Bonilla,${ }^{c}$ D. Chavarría-Bolaños, ${ }^{a}$ \\ J.R. Vega-Baudrit, ${ }^{\mathrm{d}, \mathrm{e}}$ \& V.I. Vargas ${ }^{\mathrm{b}}$ \\ ${ }^{a}$ Faculty of Dentistry and CICIMA, Universidad de Costa Rica, San José, Costa Rica; ${ }^{b}$ Plasma \\ Laboratory for Fusion Energy and Applications, Instituto Tecnológico de Costa Rica, Cartego, \\ Costa Rica; 'Faculty of Dentistry, Universidad de Costa Rica, San José, San Pedro, Costa Rica; \\ 'National Laboratory of Nanotechnology LANOTEC, San José, Costa Rica; ePOLIUNA, Univer- \\ sidad Nacional, Heredia, Costa Rica \\ *Address all correspondence to: Dr. Erika Alfaro-Mayorga, Faculty of Dentistry, Universidad de Costa Rica, San José, \\ Costa Rica; Tel.: +(506)8834-3280, E-mail: erika.alfaro@ucr.ac.cr
}

\begin{abstract}
Atmospheric-pressure plasma (APP) has demonstrated great efficiency in eliminating bacteria and modifying tissues and surfaces, and APP offers potential treatment for surface modification. There is great interest in the many possible applications of plasma in medicine and dentistry, and the interaction between plasma and tissues at physical and chemical levels depends on the plasma source. The effects of an experimental alternating-current plasma device (DIBA device, Plasma Innova, Costa Rica) on dentin or enamel have not yet been tested. With an aim to uncover new alternatives for preserving and improving longevity of the tooth restoration interface, we study effects of modifying dentin surface with atmospheric plasma at different exposure intervals.
\end{abstract}

KEY WORDS: enamel, dentin, atmospheric-pressure plasma, cold plasma

\section{INTRODUCTION}

The longevity and integrity of dentin adhesion to adhesive restorations has been questioned in recent years. The interphase between adhesive system and dentin is known as the hybrid layer. Degradation of this layer has been found in in vitro studies up to 1 yr after restoration. ${ }^{1}$ Hybrid layer degradation is related to long-term deterioration. ${ }^{1-5}$

The quality and durability of this interphase has been associated with capacity of the resin monomer to penetrate into demineralized dentin via acid, among other factors. Insufficient penetration of monomer resin results in unprotected zones that are left in the collagen, which can have a role in conversion into collagen hydrolysis by derived metalloproteinases (MMPs) from the dentin matrix. Dental cavities host multiple interacting factors, such as bacteria presence and a surface that must be modified or cleaned with acid so that an adhesive system provides retention to restorative material. ${ }^{1}$

Adhesive systems used in dentistry to bond restorative materials to dentin include a two-step total etch or a one-step self-adhesive. Both have the capacity to activate MMPs after adhesion. ${ }^{6,7}$ With the passage of time, activated MMPs can hydrolyze unprotected fibers of collagen that may be left unfilled during formation of the hy- 
brid layer. Degradation of the hybrid layer in vitro has been observed up to $1 \mathrm{yr}$ after restoration. ${ }^{1}$

Therapy with nonthermic plasma or atmospheric-pressure plasma (APP) has shown great efficiency in eliminating bacteria and modifying tissues and surfaces. In dentistry, several applications have been studied, such as disinfection of cavities and root canals, ${ }^{8,9}$ adhesion of compound resins to teeth that show improvement in the strength of adhesion, ${ }^{10,11}$ favorable adhesion force of fiber posts, ${ }^{12}$ and positive effects on microorganisms in the oral cavity, such as Lactobacillus casei, Streptococcus mutans, Candida albicans, and Escherichia coli. ${ }^{13}$ Reduced bacterial population is associated with increased exposure time. The therapy has also been used for tooth whitening and has demonstrated that an increment of the action could be attributed to the production of hydrogen peroxide. ${ }^{14}$ Treatment of the material surface can increase force of adhesion in indirect restorations, associated with the production of carboxyl groups on the surface of ceramic and better hydrophilicity that augmented with increased exposure time. ${ }^{15}$ Efforts to modify bond

strength or reduce possible deterioration of the hybrid layer necessarily result in better sealing and extent of interphase dentin restoration. Although there is interest in possible applications of plasma in medicine and dentistry, doubts still exist regarding mechanisms involved in the interaction between plasma and tissues at physical and chemical levels. The purpose of this study is to characterize physical and chemical effects of treatment with APP in the dentin surface at different exposure times.

\section{METHODS}

This in vitro experimental study included healthy third molars that were recently extracted. Exclusions were made in the cases where teeth included caries, restorations, and fractures. The same tooth was designated as the control (untreated dentin), and the positive control was dentin treated with $\mathrm{H}_{3} \mathrm{PO}_{4}$

\section{A. Sample Preparation}

Twelve third molars were collected from previously extracted teeth. The teeth were checked visually under lamplight at $2.5 \times$ magnification. Samples were stored for no more than 1 mo in deionized Milli-Q water (Millipore Corp; Burlington, MA). All teeth were cut horizontally and occluso-apical using an Isomet 5000 diamond saw (Buehler; Lake Bluff, IL) to obtain the dentin discs. We made two cuts of $2.6 \mathrm{~mm}$ each toward the apical. Encountered surfaces were evaluated, and each was randomly assigned to one of four groups (Table 1). Samples were polished with silicon carbide 600-grit abrasive paper, under humidity.

\section{B. Treatment with APP}

Plasma treatment was performed with the DIBA device, an experimental alternatingcurrent plasma device (Plasma Innova, Costa Rica). An atmospheric nonthermal al- 
TABLE 1: Distribution of dentinal surfaces to evaluate

\begin{tabular}{|l|l|l|}
\hline Group 1 & $\begin{array}{l}\text { Surface } \\
\text { Treatment }\end{array}$ & Procedure \\
\hline Group 2 & $\mathrm{H}_{3} \mathrm{PO}_{4}$ at $37 \%$ & $\begin{array}{l}\text { B: Remove excess water with paper towel, apply } \mathrm{H}_{3} \mathrm{PO}_{4} 37 \% \\
\text { Scotchbond (3M ESPE; St. Paul, MN) for 15 s, and rinse } \\
\text { copiously with water spray for 30 s }\end{array}$ \\
\hline Group 3 & $\begin{array}{l}\mathrm{Plasma}, 30 \mathrm{~s} \\
\text { C: Remove excess water with paper towel, place samples } 6 \\
\text { mm away from tip of plasma jet, and treat with plasma for } \\
30 \mathrm{~s}\end{array}$ \\
\hline Group 4 & $\begin{array}{l}\mathrm{H}_{3} \mathrm{PO}_{4} \text { at } 37 \%+ \\
30 \mathrm{~s}_{\text {plasma }}\end{array}$ & $\mathbf{B}+\mathbf{C}$ \\
\hline
\end{tabular}

For mean contact angles and standard deviations, different upper case letters indicate differences between lines (time of exposure), and different lower case letters show differences between columns (treatments); $(\mathrm{p}<0.05)$

ternating-current plasma jet source allowed us to control gas flow, voltage, and time of exposure. We operated with a flux range of ultrahigh-purity argon at 15.000 standard $\mathrm{cm}^{3} / \mathrm{min}$ and $45.9-\mathrm{W}$ power. The device was configured like a dielectric barrier discharge jet apparatus with a cooper inner electrode and 6-mm discharge tube width. Plasma was generated by high voltage of $\sim 5.6 \mathrm{kV}$ that corresponded to $28 \%$ of the device's power capacity. We set the duty cycle at $100 \%$ with a working frequency of $\sim 23 \mathrm{kHz}$.

\section{Surface Morphology}

\section{Scanning Eectron Microscopy Analysis}

Samples were placed in a copper sample holder and covered with a 5-nm gold cap. The morphological characterization of sample surface was performed using scanning electron microscopy (SEM) using a TM-3000 (HITACHI; Tokyo, Japan) at four different magnifications $(500 \times, 800 \times, 1500 \times$, and $2000 \times)$.

\section{Profilometry Analysis}

Surface roughness (Ra) was evaluated with an optical Profilometer Zeta 20 (Zeta Instruments; San Jose, CA). We determined surface mean rugosity (Ra) using an arithmetic average of the roughness profile.

Volume 8, Issue 4, 2018 


\section{Surface Wettability Analysis}

We measured the contact angle of a drop of distilled water over a dentine surface after receiving the treatments described in Table 1 with a goniometer model 200-F4 (raméhart instrument co., Succasunna, NJ). One drop of the $5 \mathrm{~mL}$ deionized water was dispensed over the surface, and distance from the surface was constant in all cases. We calculated contact angle from an image obtained from a charge-coupled device using Drop Image software (ramé-hart instrument co.).

\section{E. Raman Spectroscopy}

We used a thermo Raman spectrometer. Monochromatic radiation was emitted by a $\mathrm{He}-\mathrm{Ne}$ laser $(633 \mathrm{~nm})$ with power of excitation at $3 \mathrm{~mW}$. The spectrometer focused with an Olympus objective of $100 \times$ in the center of each sample, with intervals of $1 \mu \mathrm{m}$.

\section{STATISTICALANALYSIS}

For descriptive analyses of surface modification, rugosity, and chemical composition, we calculated means, standard deviation, and percentages. Variation in wettability of the dentinal-treated surface was considered as a continuous variable. We used student $t$ tests and performed analysis of variance.

\section{RESULTS AND DISC USSION}

\section{A. Dentin Mophology}

Representative SEM images with different treatments and at different magnifications are presented in Fig. 1. Dentin treated with plasma showed smoother surfaces compared to untreated surfaces, indicating minimal surface changes. Rugosity as arithmetical media of samples, treated or untreated with plasma for $30 \mathrm{~s}$, confirms what is shown in the SEM samples: The surface treated with plasma is smoother, as shown in Fig. 2. Morphological changes in dentin and enamel were detected by laser scanning. $\mathrm{Ra}$ decreased in dentin treated with plasma by $0.18 \%$ more than the surface treated with acid.

\section{B. Wettability}

Wettability of samples treated with plasma did not improve with treatment of plasma, regardless of exposure time. Wettability is shown in Table 2. On enamel with 10-s exposure, no difference was found with $p>0.05$ between treatment groups. In the 20 -s group, dentin with acid and dentin with acid and plasma were significantly less wettable than those without treatment or only treated with plasma. 

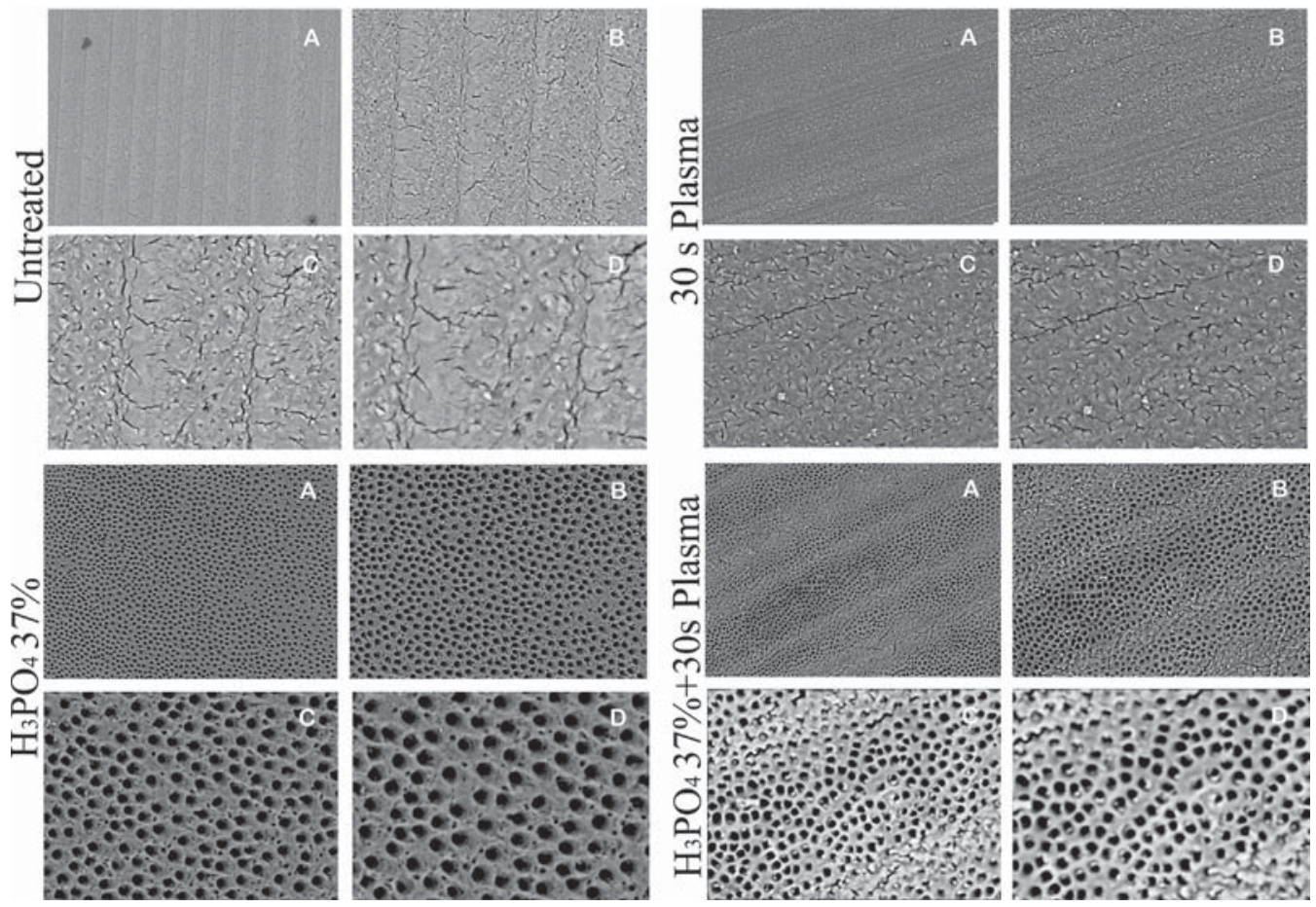

FIG. 1: SEM Analysis of treated dentin and enamel surfaces. (A) 500×, (B) $800 \times$, (C) $1500 \times$, and (D) $2000 \times$

\section{Raman Spectroscopy}

Figure 3 shows Raman spectral changes of sliced human dentin after various surface treatments at three different time intervals. The intensity of the signal for $\mathrm{PO}_{4}$ was superior between groups in specimens treated with plasma for $30 \mathrm{~s}$. This can be due to the increased inorganic material in enamel over that in dentin. ${ }^{15,16}$
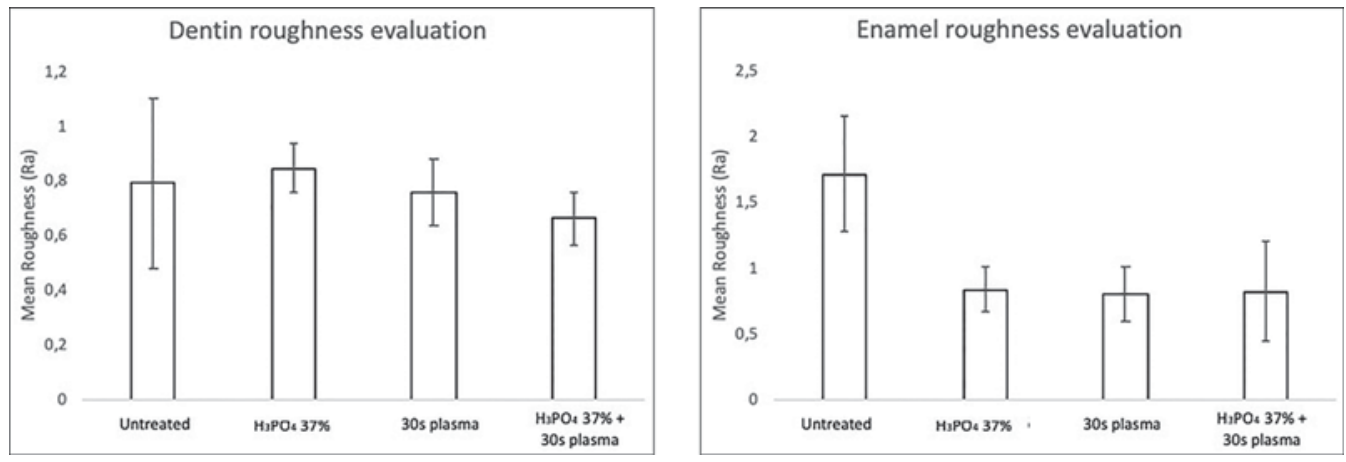

FIG. 2: Ra of dentin and enamel treated with plasma, determined by profilometer

Volume 8, Issue 4, 2018 


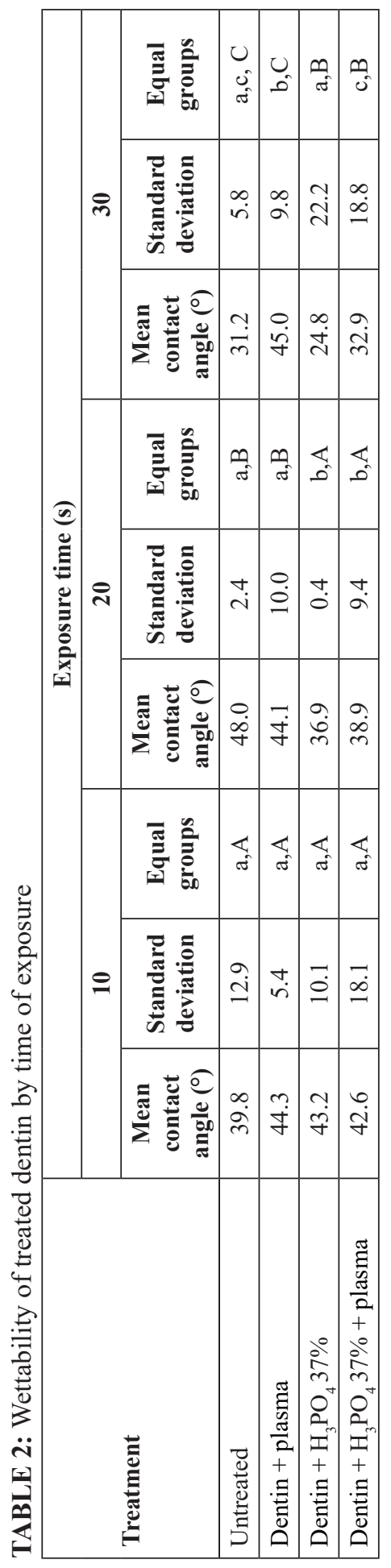



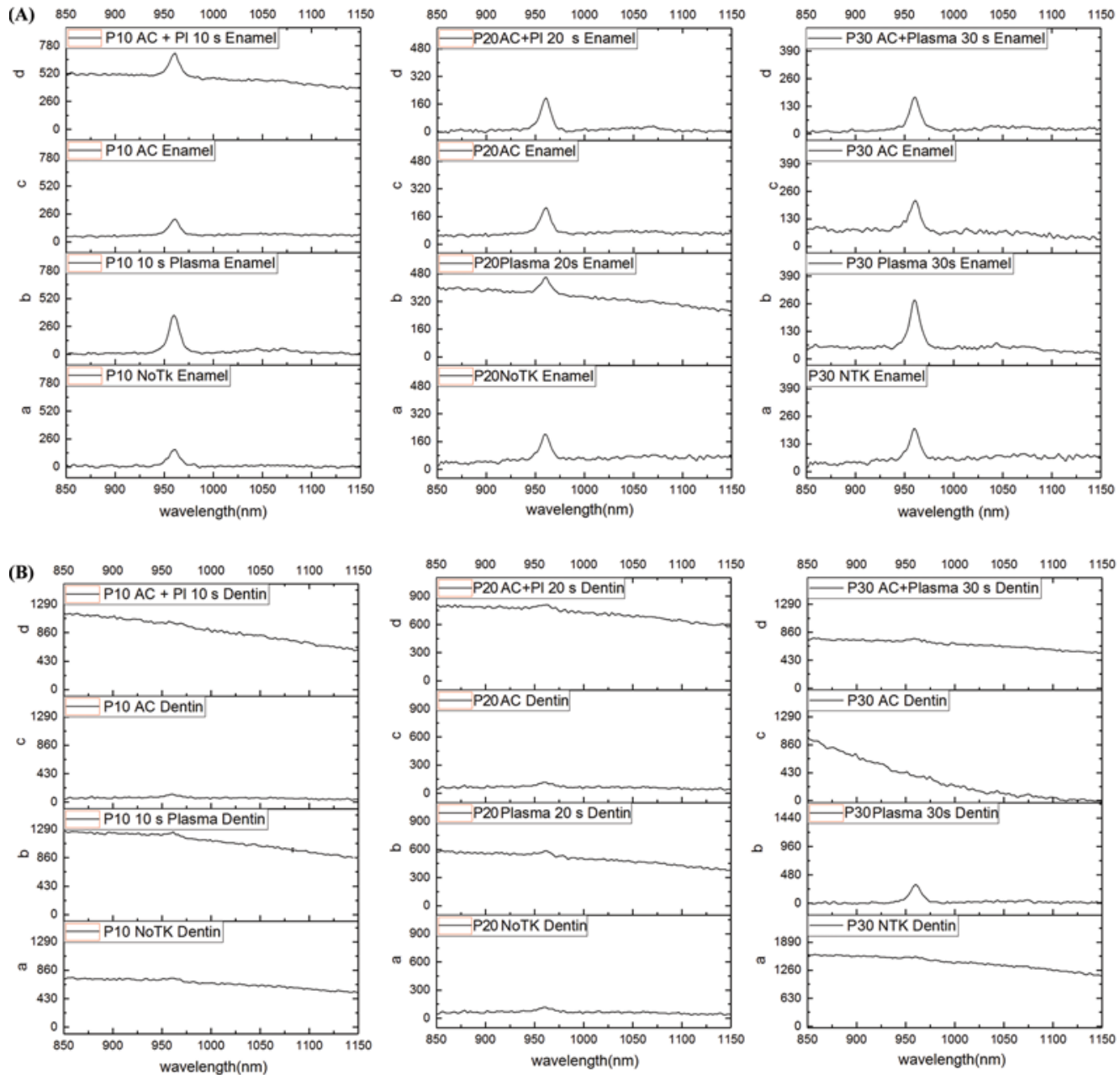

FIG. 3: Raman spectral changes of human dentin and enamel. (a) No treatment; (b) plasma treatment for 10, 20, or $30 \mathrm{~s}$; (c) $\mathrm{H}_{3} \mathrm{PO}_{4}$ at $37 \%$ treatment for $15 \mathrm{~s}$; (d) $\mathrm{H}_{3} \mathrm{PO}_{4}$ at $37 \%$ treatment for 15 $\mathrm{s}$ and plasma treatment for 10,20 , or $30 \mathrm{~s}$

These preliminary results demonstrate that plasma treatment can modify chemical and physical structure of dental tissues. The impact of these changes must be validated in further studies to analyze its biological influence over organic surrounding tissues and its effects in bonded restorative treatments.

\section{ACKNOWEDGMENTS}

This research was supported by a CONARE (Consejo Nacional de Rectores) FEES (Fondo especial para la Educación Pública) fund (Grant No. 440 B6 651). The authors are grateful for the support of this work presented at the 7 th International Conference

Volume 8, Issue 4, 2018 
on Plasma Medicine, sponsored by the Vicerrectoría de Investigación y Extensión of the Institute of Technology of Costa Rica and Vicerrectoría de Investigación University of Costa Rica through CONARE's FEES Fund.

\section{REFERENCES}

1. Pashley DH, Tay FR, Yiu C, Hashimoto M, Breschi L, Carvalho RM, Ito S. Collagen degradation by host-derived enzymes during aging. J Dental Res. 2004;83(3):216-22.

2. De Munk J. A critical review of the durability of adhesion to tooth tissue: Methods and results. J Dental Res. 2005;84(2):118-32.

3. De Munk J, Mine A, Van den Steen PE, Van Landuyt KL, Poitevin A, Opdenakker G, Van Meerbeek B. Enzymatic degradation of adhesive-dentine interfaces produced by mild self-etch adhesives. Eur J Oral Sci. 2010;118(5):494-501.

4. Osorio R, Yamauti M, Ruiz-Requena ME, Toledano M. MMPs activity and bond strength in deciduous dentine-resin bonded surfaces. J Dent. 2013;41(6):549-55.

5. Van Landuyt KL, De Munck J, Mine A, Cardoso MV, Peumans M, Van Meerbeek B. Filler debonding and sub hybrid-layer failures in self-etch adhesives. J Dent Res. 2010;89(10):1045-50.

6. Van Meerbeek B, Conn LJ, Jr, Duke ES, Eik JD, Robinson SJ, Guerrero D. Correlative transmission electron microscopy examination of non-demineralized and de-mineralized resin-dentine interfaces formed by two dentine adhesive systems. J Dent Res. 1996;75(3):879-88.

7. Sladek REJ, Stoffels E, Walraven R, Tielbeek PJA, Koolhoven RA. Plasma treatment of dental cavities: A feasibility study. IEEE Trans Plasma Sci. 2004;32(4):1540-3.

8. Lu X, Cao Y, Yang P, Xiong Q, Xiong Z, Xian Y, Pan Y. An RC plasma device for sterilization of root canal of teeth. IEEE Trans Plasma Sci. 2009;37(5):668-73.

9. Kong MG, Kroesen G, Morfill G, Nosenko T, Shimizu T, van Dijk J, Zimmermann JL. Plasma medicine: An introductory review. New J Phys. 2009;11:115012.

10. Dong X, Ritts AC, Staller C, Yu Q, Chen M, Wang Y. Evaluation of plasma treatment effects on improving adhesive-dentin bonding by using the same tooth controls and varying cross sectional surface areas. Eur J Oral Sci. 2013;121:355-62.

11. Yavirach P, Chaijareenont P, Boonyawan D, Pattamapun K, Tunma S, Takahashi H, Arksornnukit M. Effect of plasma treatment on the shear bond strength between fiber enforced composite posts and resin composite for core build up. Dent Mat J. 2009;28(6):686-92.

12. Rupf S, Lehmann A, Hannig M, Schäfer B, Schubert A, Feldmann U, Schindler A. Killing of adherent oral microbes by a non-thermal atmospheric plasma jet. J Med Microbiol. 2010;59:206-12.

13. Lee HW, Kim GJ, Kim JM, Park JK, Lee JK, Kim GC. Tooth bleaching with nonthermal atmospheric pressure plasma. J Endod. 2009;35(4):587-91.

14. Han GJ, Chung SN, Chun BH, Kim CK, Oh KH, Cho BH. Effect of the applied power of atmospheric pressure plasma on the adhesion of composite resin to dental ceramic. Adhes Dent. 2012;14:461-5.

15. Lehmann A, Rueppell A, Schindler A, Zylla I-M, Jürgen Seifert H, Nothdurft F, Hannig M, Rupf S. Modification of enamel and dentin surfaces by non-thermal atmospheric plasma. Plasma Proc Polym. 2013;10(3):262-70.

16. Tsuda H, Arends J. Raman spectroscopy in dental research: A short review of recent studies. Adv Dent Res. 1997;11(4):539-47. 